\title{
Effects of Sodium-Heparin and Dipotassium EDTA on the Haematological Parameters and Blood Cell Morphology of Freshwater Fish Schizothorax labiatus (Mcclelland, 1842)
}

\author{
Imtiaz Ahmed* and Amir Maqbool \\ Fish Nutrition Research Laboratory \\ Department of Zoology, University of Kashmir, Hazratbal, Srinagar (J.K.), India
}

\begin{abstract}
The present study was conducted with an aim of evaluating the effects of sodium-heparin (20 $1 . U / \mathrm{ml})$ and di-potassium EDTA $(1.0 \mathrm{mg} / \mathrm{ml})$ on the haematological parameters and blood cell morphology of freshwater fish Schizothorax labiatus. For blood sampling, fifteen fishes of uniform weight $(250 \pm 18.5$ g) and length $(25 \pm 2.1 \mathrm{~cm})$ were selected. All the haematological analysis were carried out immediately after sampling. An increase in the haematocrit level was observed in the samples collected with $K_{2} E D T A$. Red blood cell counts were lower in $K_{2} E D T A$ collected samples as compared to heparinized samples. The $W B C$ counts and haemoglobin concentrations did not differ significantly ( $p>0.05)$. Mean corpuscular haemoglobin $(\mathrm{MCH})$ and mean corpuscular volume $(\mathrm{MCV})$ increased in $\mathrm{K}_{2} E D T A$ sample, while a significant decrease $(p<0.05)$ was observed in mean corpuscular haemoglobin concentration $(\mathrm{MCHC})$. Cell morphometric analysis showed an increase in the RBC area in samples treated with $K_{2} E D T A$ as compared to heparinized sample. There was however, no significant difference ( $p>0.05)$ observed in WBC and thrombocyte area of $K_{2} E D T A$ and heparinized sample. The present study suggests the use of Na-heparin as a preferred anticoagulant for routine haematological analysis of fish blood.
\end{abstract}

Keywords: Sodium-heparin, Di-potassium EDTA, Haematological analysis, Cell morphology.

\section{Introduction}

In recent time haematological and immunological study of fish has assumed greater significance due to the increasing emphasis on fish culture and greater awareness of the pollution of natural fresh water resources (Blaxhall, 1972). Haematological and biochemical parameters are used as health indicators to detect the structural and functional status of fish under stress condition (Pimpao et al., 2007; Suvetha et al., 2010). The haematological characteristics have also been used as diagnostic tool to evaluating physiological changes including fish health (Satheeshkumar et al., 2010,). Many automatic clinical tools have been developed for mammalian haematological analysis, but due to the unavailability of these automatic tools for fish, manual methods are employed.
The interpretation of blood parameters is quite difficult, since variations in the blood are caused by internal and external factors including anticoagulants used, method of analysis, the storage temperature, and the time lapse between sample analyses. Fish blood contains a large number of thrombocytes due to which it clots quickly, and samples almost always require anticoagulant treatment. Anticoagulants are additives that inhibit the clotting of blood and thereby ensure that the concentration of the substance to be measured is changed as little as possible before the analytical process (Guder, 2001). Blood cells of various animals show different reactions to various anticoagulants (Witeska and Wargocka, 2011). In fish haematology the most commonly used anticoagulants are different salts of heparin and EDTA (Walencik and Witeska, 2007). EDTA acts by 
binding calcium ions, which are essential in the coagulation cascade and for cell-to-cell interaction. Due to this property, the EDTA salt is used as a blood anticoagulant because it chelates calcium ions which promote blood clotting (Jain, 1993). Heparin binds to and accelerates the activity of antithrombin III, which inhibits the action of thrombin and other proteases necessary for coagulation (Harr et al., 2005).

Many workers have used EDTA salts as most appropriate for fish blood analyses (Blaxhall and Daisley, 1973; Sala-Rabanal Jalis 2003), while others recommend heparin as the preffered anticoagulant (Walencik and Witeska, 2007; Ishikawa et al., 2010; Clark et al., 2011) . Haematology provides useful information as long as the addition of an anticoagulant causes no alteration. The aim of the present study was to study the effects of sodium-heparin and di-potassium-EDTA on the haematological parameters and blood cell morphology of Schizothorax labiatus so as to suggest the better anticoagulant for routine fish blood analysis.

\section{Materials and Methods}

\section{Experimental Fish}

Adult specimens of Schizothorax labiatus (McClelland, 1842) weighing $250 \pm 18.5 \mathrm{~g}$ and average length $25 \pm 2.1 \mathrm{~cm}$ were obtained from a local fish farm. The fish were transported in polythene bags filled with water and oxygen and brought to wet laboratory at the Department of Zoology, University of Kashmir. To rule out any possible microbial infection, the fish were given a prophylactic dip in $\mathrm{KMnO}_{4}$ (5 $\left.\mathrm{mg} \mathrm{L}^{-1}\right)$ and stocked in indoor circular fish tank (water volume $=600 \mathrm{~L}$ ) at $16.6 \pm 1.4^{\circ} \mathrm{C}$, D.O $6.6 \mathrm{mgL} \pm 1$ and $\mathrm{pH} 7.1-7.5$ with $12: 12 \mathrm{~h}$ photoperiod.

\section{Blood Sampling and Anticoagulant Treatment}

During blood sampling, fishes were netted carefully imparting minimum stress and placed in a fish trough. Using a chilled needle fitted to a $3 \mathrm{ml}$ syringe, blood was drawn from the caudal vein. Blood smears were made on the spot from anticoagulant free blood, which were used as control to be compared against the blood smears prepared from anticoagulant treated blood. Blood sample was equally transferred to sterilized blood collection tubes, containing the respective anticoagulant i.e., Na-Heparin $(20 \mathrm{I} . \mathrm{U} / \mathrm{ml})$ and $\mathrm{K}_{2}$ EDTA $(1.0 \mathrm{mg} / \mathrm{ml})$ which were prepared by dissolving the dry salts of $\mathrm{Na}-\mathrm{Hep}$ arin and $\mathrm{K}_{2}$ EDTA (Loba Chemie, India) in phosphate buffer saline (PBS, pH 6.8). Blood vials were kept in an ice-bath until further analysis. All the haematological parameters were analyzed within 2 hours after sample collection.

\section{Total Erythrocyte Count (RBC) and Total Leucocyte Count (WBC)}

$\mathrm{RBC}$ and WBC counts were done simultaneously in a neubauer haemocytometer with Natt Herrick's (1952) diluent (1:200). The blood cell counting was done under a microscope.

\section{Haemoglobin ( $\mathrm{Hb})$}

Drabkin's cyanomethemoglobin method (1946) was used to estimate the haemoglobin content of the blood. $20 \mu \mathrm{l}$ of blood was mixed with $5 \mathrm{ml}$ of Drabkin's reagent (Loba Chemie, India), left to stand for 15 minutes and then absorbance measurement was done at $540 \mathrm{~nm}$. Absorbance of test sample was plotted against that of haemoglobin standard (Ranbaxy India) to get the haemoglobin concentration. Haemoglobin test samples were centrifuged, prior to reading the absorbance, to remove dispersed nuclear material.

\section{Haematocrit (Hct)}

Blood samples $(50 \mu l)$ were taken in micro haematocrit capillaries and centrifuged in a micro centrifuge (REMI RM-12C BL, India) spun in at $12,000 \mathrm{rpm}$ for $5 \mathrm{~min}$ to obtain haematocrit value which were reported as percentage. Blood indices including mean cor- 
puscular volume (MCV), mean corpuscular haemoglobin $(\mathrm{MCH})$ and mean corpuscular haemoglobin concentration $(\mathrm{MCHC})$ were calculated from $\mathrm{RBC}$, Hct and $\mathrm{Hb}$ according to the following formulae: $\mathrm{MCV}=(\mathrm{PCV} \times 10) / \mathrm{RBC}$, $\mathrm{MCH}=(\mathrm{Hb} \times 10) / \mathrm{RBC}$ and $\mathrm{MCHC}=(\mathrm{Hb} \times$ 100)/ Hct (Dacie and Lewis, 1991).

\section{Blood Cell Morphology}

Using grease free glass slides, two blood smears were prepared for each blood sample. After air drying, the smears were fixed in $100 \%$ methanol for 5-8 min and stained with May-Grunwald-Giemsa stain. Using a compound microscope (Magnus MLX-Tr, India) blood smears were examined at 1000x magnification. Digital microphotographs were obtained with a digital DSLR camera (Cannon EOS 70D) attached to microscope and blood cell morphometric analysis was done with 'ImageJ' image analysis software (National Institute of Health) calibrated to a stage micrometer.

\section{Statistical Analysis}

All statistical analyses were carried out with SPSS 11.5 (SPSS Inc., Chicago, IL, USA). Haematological parameters were summarized as mean \pm standard deviation (SD) and differences between $\mathrm{Na}$-heparin and $\mathrm{K}_{2}$ EDTA anticoagulated blood samples were statistically analyzed using the Student's t-test. Results were considered significant at $p<0.05$.

\section{Results and Discussion}

\section{Haematological Parameters}

Table 1 shows the result of the blood samples treated with Na-Heparin $(20 \mathrm{I} . \mathrm{U} / \mathrm{ml}$ of blood) and $\mathrm{K}_{2}$ EDTA ( $1.0 \mathrm{mg} / \mathrm{ml}$ of blood). Haematocrit values in all $\mathrm{K}_{2}$ EDTA treated samples were significantly higher $(p<0.05)$ and much more variable compared to those of heparin collected samples. The total RBC counts between blood samples obtained with $\mathrm{K}_{2}$ EDTA and those obtained with $\mathrm{Na}$ Heparin showed Significant $(p<0.05)$ differences. Mean corpuscular volume (MCV) was increased in $\mathrm{K}_{2}$ EDTA sample, while a significant decrease $(p<0.05)$ was found in mean corpuscular haemoglobin concentration $(\mathrm{MCHC})$. Haemoglobin concentration, total WBC counts and leucocyte morphology did not differ significantly $(p>0.05)$ among the samples treated with Na-heparin and $\mathrm{K}_{2}$ EDTA.

\section{Cell Morphometric Analysis}

Characterization and identification of blood cells was done by light microscopy. Blood smear analysis revealed considerable erythrocyte swelling leading to significant enlargement in all the $\mathrm{K}_{2}$ EDTA treated samples (Fig. 1d) as compared to the untreated blood samples (Fig. 1a and 1b), while in heparinized samples, most of the erythrocytes were normal and intact (Fig. 1c). In $\mathrm{Na}_{2}$ EDTA treated samples, bare nuclei released by haemolyzed erythrocytes were also observed (Fig. 1d). Leukocytes in $\mathrm{K}_{2}$ EDTA and Na-Heparin anticoagulated blood showed no morphological changes.

An elevation in haematocrit values and a decrease in haemoglobin concentration and RBC counts were observed in $\mathrm{K}_{2}$ EDTA treated samples. $\mathrm{K}_{2}$ EDTA also induced RBC swelling and erythrocyte haemolysis, while no significant change of haematological parameters was observed in Na-heparin treated samples. Similar observations were reported by Walencik and Witeska (2007) and Ishikawa et al. (2010). EDTA salt can cause acidification and an increase in $\mathrm{pCO}_{2}$ (Smit et al., 1977), due to which haematocrit levels might have elevated. This phenomenon was observed by Korcock et al (1988), Walencik and Witeska (2007) and Witeska and Wargocka (2011). Hattingh (1975) compared the effects of heparin and EDTA on haematocrit of five species of fish and found that EDTA had a tendency to increase haematocrit in fish, and in some species induced 
Table 1 Hematological parameters of Schizothorax labiatus (McClelland, 1842) $(n=15)$ treated with anticoagulant sodium-heparin (20 I.U/ml of blood) and di-potassium-EDTA $(1.0 \mathrm{mg} / \mathrm{ml} \text { of blood })^{*}$

\begin{tabular}{|c|c|c|c|c|c|c|c|}
\hline $\begin{array}{l}\text { Anticoagulant } \\
\text { used }\end{array}$ & Hct (\%) & $\mathrm{Hb}\left(\mathrm{gdl}^{-1}\right)$ & $\begin{array}{c}\text { RBC } \\
\left(\times 10^{6} / \mathrm{mm}\right)\end{array}$ & $\begin{array}{c}\text { WBC } \\
\left(x 10^{3} / \mathrm{mm}\right)\end{array}$ & $\operatorname{MCV}(\mathrm{fl})$ & $\mathrm{MCH}(\mathrm{pg})$ & MCHC $\left(\mathrm{gdl}^{-1}\right)$ \\
\hline Na-Heparin & $34.32 \pm 2.01^{\mathrm{a}}$ & $8.19 \pm 0.43^{a}$ & $1.42 \pm 0.07^{a}$ & $12.18 \pm 3.20^{a}$ & $241.1 \pm 8.96^{\mathrm{a}}$ & $57.59 \pm 1.16^{a}$ & $23.91 \pm 1.31^{\mathrm{a}}$ \\
\hline $\mathrm{K}_{2}$ EDTA & $39.20 \pm 1.95^{b}$ & $6.90 \pm 0.70^{a}$ & $1.22 \pm 0.06^{\mathrm{b}}$ & $11.45 \pm 2.71^{a}$ & $321.4 \pm 8.38^{b}$ & $56.45 \pm 2.77^{a}$ & $17.57 \pm 1.01^{b}$ \\
\hline
\end{tabular}

Hct, Haematocrit; Hb, Haemoglobin concentration; RBC, Red blood cell count; WBC, White blood cell count; MCV, Mean corpuscular volume; $\mathrm{MCH}$, Mean corpuscular haemoglobin; MCHC, Mean corpuscular haemoglobin concentration;

Values are mean $\pm \mathrm{SD}$. Means with different superscripts are significantly different $(p<0.05)$
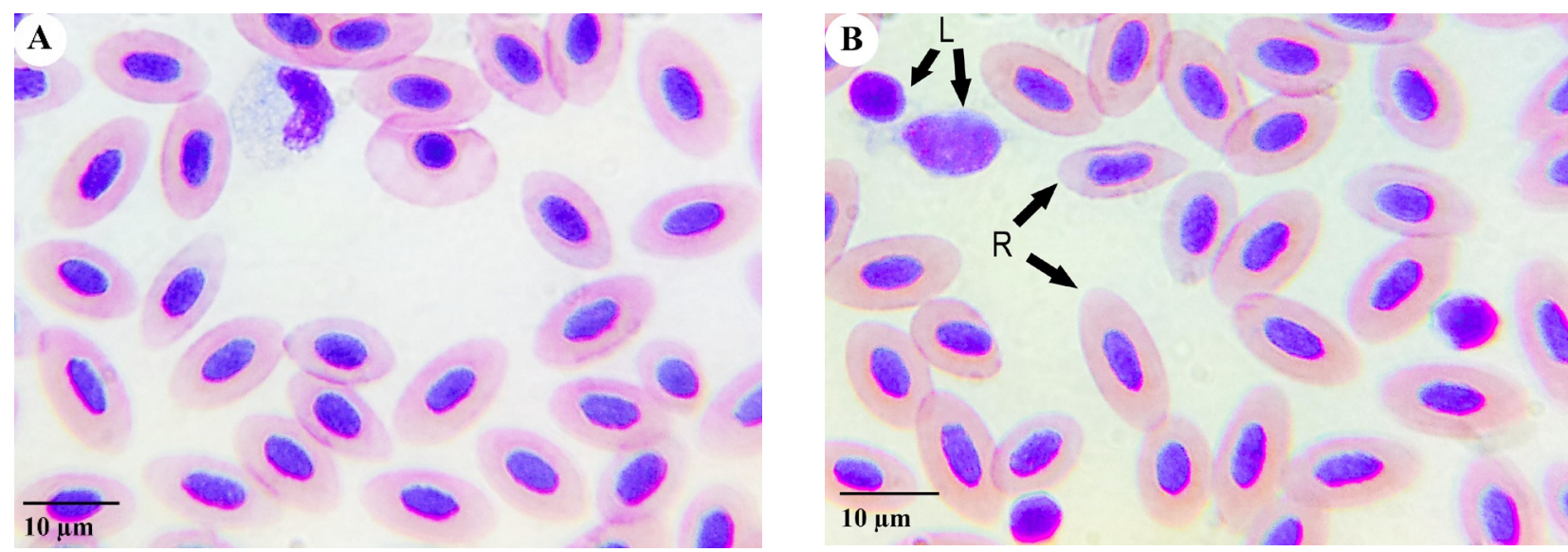

C

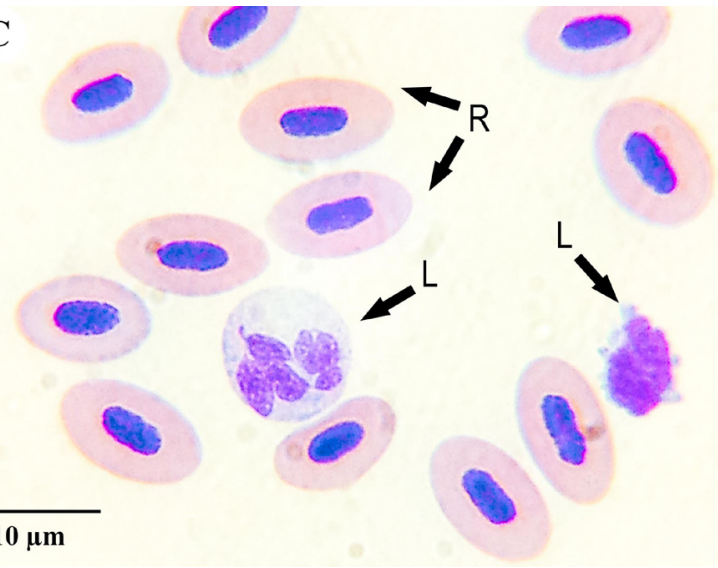

D

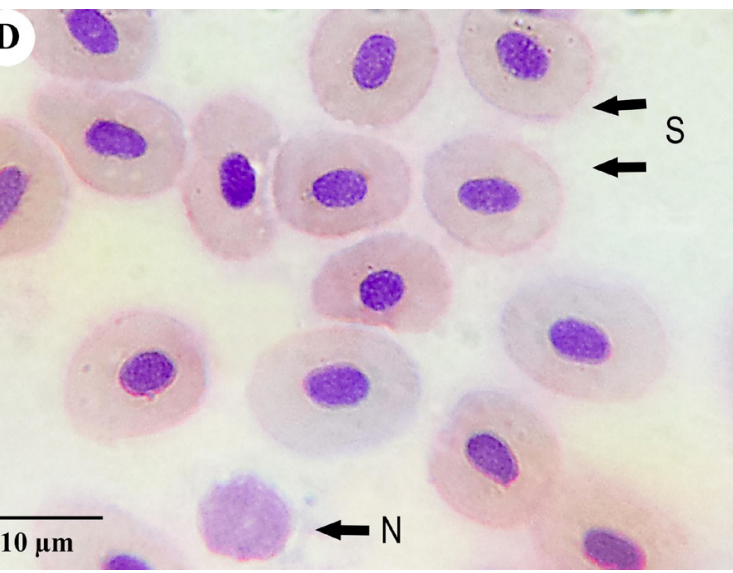

Fig. 1. Light micrographs of May-Grunwald-Giemsa stained blood film of Schizothorax labiatus (McClelland, 1842). A and B: Control, showing normal and intact erythrocytes (R); C: Na-heparin treated, showing normal and intact erythrocytes $(R)$ and leucocytes $(L) ; D: K_{2} E D T A$ treated, showing erythrocyte swelling (S) and bare erythrocyte nuclei $(\mathrm{N})$. 
haemolysis, while heparin produced very little change in erythrocyte volume and haematocrit values. On incubation of blood for 20 min with $10 \mathrm{mg} / \mathrm{mL}$ of EDTA, a distortion of erythrocyte shape followed by lysis was observed in Blennius pholis (Mainwaring and Rowley, 1985). EDTA sequesters $\mathrm{Ca}^{2+}$ ions is responsible for the activation of $\mathrm{Na}^{+}$and $\mathrm{K}^{+}$ions in the cell membrane which allows the free entry of water into the cell, promoting-swelling and its consequent lysis (Jain, 1993). Heparin is known to cause little alteration in corpuscular size and is considered a more suitable anticoagulant, because its varying concentration has little effect on the PCV values ( Dubin et al., 1976). In the present study, Na-Heparin caused no significant alteration in RBC morphology, which also corroborate the observation made by Walencik and Witeska (2007), Ishikawa et al. (2010) and Witeska and Wargocka (2011) in common carp.

A decrease in RBC count in $\mathrm{Na}_{2}$ EDTA treated samples was observed in the present study, which could be due to the haemolytic action of EDTA. EDTA treatment causing erythrocyte haemolysis have been reported in fish (Walencik and Witeska, 2007; Korcock et al., 1988; Lataretu, 2013) and other vertebrates (Muro et al., 1998; Antwi-Baffour et al., 2013) leading to low RBC counts and decreased haemoglobin concentration. Witeska and Wargocka (2011) observed gradual destruction of erythrocytes in $\mathrm{Na}_{2}$ EDTA samples, where $\mathrm{Na}_{2}$ EDTA caused cell swelling, followed by disintegration of the outer membranes of erythrocytes, which resulted in release of the nucleus. Erythrocytes become more susceptible to lysis as EDTA increases their osmotic fragility. Increased osmotic fragility in the blood samples treated with EDTA was observed by Walencik and Witeska (2007) in Cyprinus carpio and Mafuvadze and Erlwanger (2007) in ostritches, which eventually lead to a decrease in the RBC count. A gradual destruction of erythrocytes in $\mathrm{Na}_{2}$ EDTA samples was observed by Witeska and Wargocka (2011), where $\mathrm{Na}_{2}$ EDTA caused cell swelling, followed by disintegration of the outer membranes of erythrocytes, which resulted in release of the nucleus. Haemolytic action of EDTA can be attributed to the adverse effect of $\mathrm{Na}_{2}$ EDTA on erythrocyte membrane structure, permeability, and stability, which is probably related to decalcination induced by the chelating action of the anticoagulant (Blaxhall, 1972; Hattingh, 1975).

In conclusion Na-heparin is found as the preferable anticoagulant for blood sampling in Schizothorax labiatus as it imparts minimum changes to haematological parameters, while $\mathrm{K}_{2}$ EDTA cannot be applied as an anticoagulant for haematological analysis, since it significantly affects the haematological parameters and alters the shape and size of blood cells, affecting red blood cell parameter readings.

\section{Acknowledgements}

The authors are grateful to the Head, Department of Zoology, University of Kashmir, Hazratbal, Srinagar, India, for providing the necessary laboratory facilities and also gratefully acknowledge the generous funding from the Department of Science and Technology (DST), Govt of India, New Delhi in the form of DSTFAST Track Young Scientist Project.

\section{References}

Antwi-Baffour S., Quao E., Kyeremeh R. and Mahmood S A, (2013) Prolong storage of blood in EDTA has an effect on the morphology and osmotic fragility of erythrocytes. Int. J. Biom. Sci. Eng., 1, 20-23.

Blaxhall, P.C., (1972) Haematological assessment of the health of the freshwater fish. J. Fish Biol., 4, 592-604

Blaxhall P.C. and Daisley K.W., (1973) Routine haematological methods for use with fish blood. J. Fish Biol., 5, 771-781.

Dubin S, Piszczek J, Beard $\mathrm{R}$ and Schmukler R. (1976) Effects of anticoagulants on packed cell volume measurement. Lab Animal Sci., 26, 586-591

Guder WG (2001). The quality of diagnostic samples. Blood Gas News. 10, 18-24.

Harr K.E., Raskin R.E. and Heard D.J., (2005) Temporal effects of 3 commonly used anticoagulants on 
haematological and biochemical variables in blood samples from macaws and Burmese pythons. Veter.Clin. Pathol., 34, 383-388.

Hattingh J., (1975) Heparin and ethylenediamine tetra-acetate as anticoagulants for fish blood. Pflugers Arch., 355, 347-352.

Ishikawa M.M., Pádua S.B.D., Satake F., Hisano H. and Jerônimo G.T.,.(2010) Martins ML et al. Heparin and $\mathrm{Na}_{2}$ EDTA as anticoagulants for hybrid surubim catfish (Pseudoplatystoma reticulatum $\times$ P. corruscans): efficacy and haematological changes. Ciencia Rural., 40, 1557-1561.

Jain N.C. (1993) Coagulation and its disorders; In: Essentials of veterinary haematology (ed.) NC Jain \& Fabiger, Philadelphia pp. 82-104.

Lataretu A., (2013) Comparative study of the effect of different anticoagulants on blood cell morphology in common carp (C. carpio) and rainbow trout (O. mykiss). Bulletin of University of Agricultural Sciences and Veterinary Medicine Cluj-Napoca. Anim. Sci. Biotech., 70, 284-288.

Mafuvadze B. and Erlwanger K.H., (2007) The effect of EDTA, heparin and storage on the erythrocyte osmotic fragility, plasma osmolality and haematocrit of adult ostriches (Struthio camelus). Veterinarski Arhiv., 77, 427-434.

Mainwaring G. and Rowley A.F., (1985) The effect of anticoagulants on Blennius pholis L. leucocytes. Comp. Biochem Physiol Part A: Physiology., 80, 85-91.

Muro J., Cuenca R., Pastor J., Vinas L. and Lavin S., (1998) Effects of lithium heparin and tripotassium
EDTA on haematologic values of Hermann's tortoises (Testudo hermanni). J. Zool. Wildlife Medi., 29, 40-44.

Pimpao C.T, Zampronio A.R and Silva de Assis H.C. (2007) Effects of deltamethrin on haematological parameters and enzymatic activity in Ancistrus multispinis (Pisces, Teleostei). Pestic. Biochem Physiol., 88 122-127.

Sala-Rabanal M., Sánchez J., Ibarz A., Fernández-Borràs J., Blasco J. and Gallardo M.A. (2003) Effects of low temperatures and fasting on haematology and plasma composition of gilthead sea bream (Sparus aurata). Fish Physiol. Bioch., 29, 105-115.

Satheeshkumar P., Ananthan G., Senthilkumar D. and Khan A.B., Jeevanantham K..(2010) Comparative investigation on haematological and biochemical studies on wild marine teleost fishes from Vellar estuary, southeast coast of India. Comp. Clin. Path., 21, 275-281

Suvetha, L. Ramesh, M. and Saravanan, M. (2010) Influence of cypermethrin toxicity on ionic regulation and gill $\mathrm{Na}+/ \mathrm{K}+-$ ATPase activity of a freshwater teleost fish Cyprinus carpio. Environ. Toxic. Pharm., 29, 44-49.

Walencik J. and Witeska M. (2007) The effects of anticoagulants on haematological indices and blood cell morphology of common carp (Cyprinus carpio L.). Comp. Biochem. Physiol. Part C: Toxic. Pharmacol.,146, 331-335.

Witeska M and Wargocka W. (2011) Disodium EDTA used as anticoagulant causes hemolysis in common carp blood. Turkish J. Veter. Anim. Sci., 35, 99-104. 